\title{
Controlling the Features of Electrospun Nanofibers
}

\author{
M. I. El Gohary a, B.M. Abd El Hady ${ }^{\mathrm{b}}$, A. A. Al Saeed c, A.M. I. El Rashedi ${ }^{\text {, }}$ \\ S.I. Saleh ${ }^{\text {. }}$ \\ ${ }^{a}$ Al Azhar University, Faculty of Science (Boys), Branch of Biophysics, ${ }^{\mathbf{b}}$ National \\ Research Center, polymers and pigments Department,. ' Al Azhar University, Faculty \\ of Science(Girls), Branch of Biophysics.
}

\begin{abstract}
THE MAJOR challenge of the electrospinning process lies in the optimization of its parameters to achieve desirable nanofibers morphology and properties. The present work highlights the change of properties for electrospun poly $\varepsilon$-caprolactone and poly ethylene oxide with modulation of different parameters. The effect of solution parameters such as; concentration poly $\varepsilon$-caprolactone, concentration of poly ethylene oxide relative to poly $\varepsilon$-caprolactone, viscosity , different solvents, voltage properties and distance separates tip of the syringe and collector to fabricate poly $\varepsilon$-caprolactone electrospun nanofibers with desired morphologies is indicated in present work. Morphologies of the processed nanofibers are examined by FESEM, the average diameter of nanofibers and their normal distribution are investigated by image $\mathrm{j}$ analyzer software. Of all combinations, the best and the finest nanofibers are obtained at $10 \% \mathrm{w} / \mathrm{v}$ poly $\varepsilon$-caprolactone, $3 \% \mathrm{w} / \mathrm{v}$ poly ethylene oxide concentration with respect to that of poly $\varepsilon$-caprolactone, at voltage $20 \mathrm{kV}$ and lastly at $12 \mathrm{~cm}$ distance separate the tip of syringe and collector. Controlling the features of electrospun fibers via variation on the operating parameters, allow applications of fibers on different fields.
\end{abstract}

Keywords: Electrospinning, nanofibers, poly $\varepsilon$-caprolactone, poly ethylene oxide.

\section{Introduction}

Electrospinning is a simple and versatile technique that utilizes electrostatic forces to produce very fine fibers of polymer ranging from submicron to nanometer sizes. The technique can be applied to generate fibers of a wide array of polymer types like; synthetic, natural, biodegradable, and nondegradable or their blends. [1] Although there are other conventional techniques for polymeric fiber fabrication, but electrospinning has gained much importance and is the preferred technique since it is relatively; ease, low cost, requires simple tooling, and is applicable for producing ultrafine fibers [2]. Three basic components of electrospinning system are known; spinneret, a high voltage power source and a grounded collector (Fig. 1A).

Although the electrospinning process appears to be technically simple with ease of adaptability, a number of variables processing need to be regulated in order to generate nanofibers instead of droplets or beaded morphologies. The major challenge of the electrospinning process lies in the optimization of these parameters to achieve desirable nanofibers. [3] These parameters can be classified into three major categories (Fig. 1B); Solution parameters, process parameters and ambient parameters. Solution parameters include: concentration, molecular weight, viscosity, surface tension, conductivity and type of solvent. Processing parameters consist of; voltage, flow rate, collectors, distance separates collector and tip of the syringe. Ambient parameters include; humidity, temperature. All of these indices affect the trigger formation of the fiber out of the polymer solution and also influence the required fiber diameter in addition to morphology for specified application.

The present study aims to investigate the factors influence the properties of fiber mat fabricates using Polycaprolactone (PCL) and polyethylene oxide (PEO). PCL is a semicrystalline, highly hydrophobic polymer that is easily soluble in most organic solvents, and has been approved by the Food and Drug Administration (FDA) for biomedical applications [4]. PEO is an amphiphilic, watersoluble, and nondegradable polymer with good 

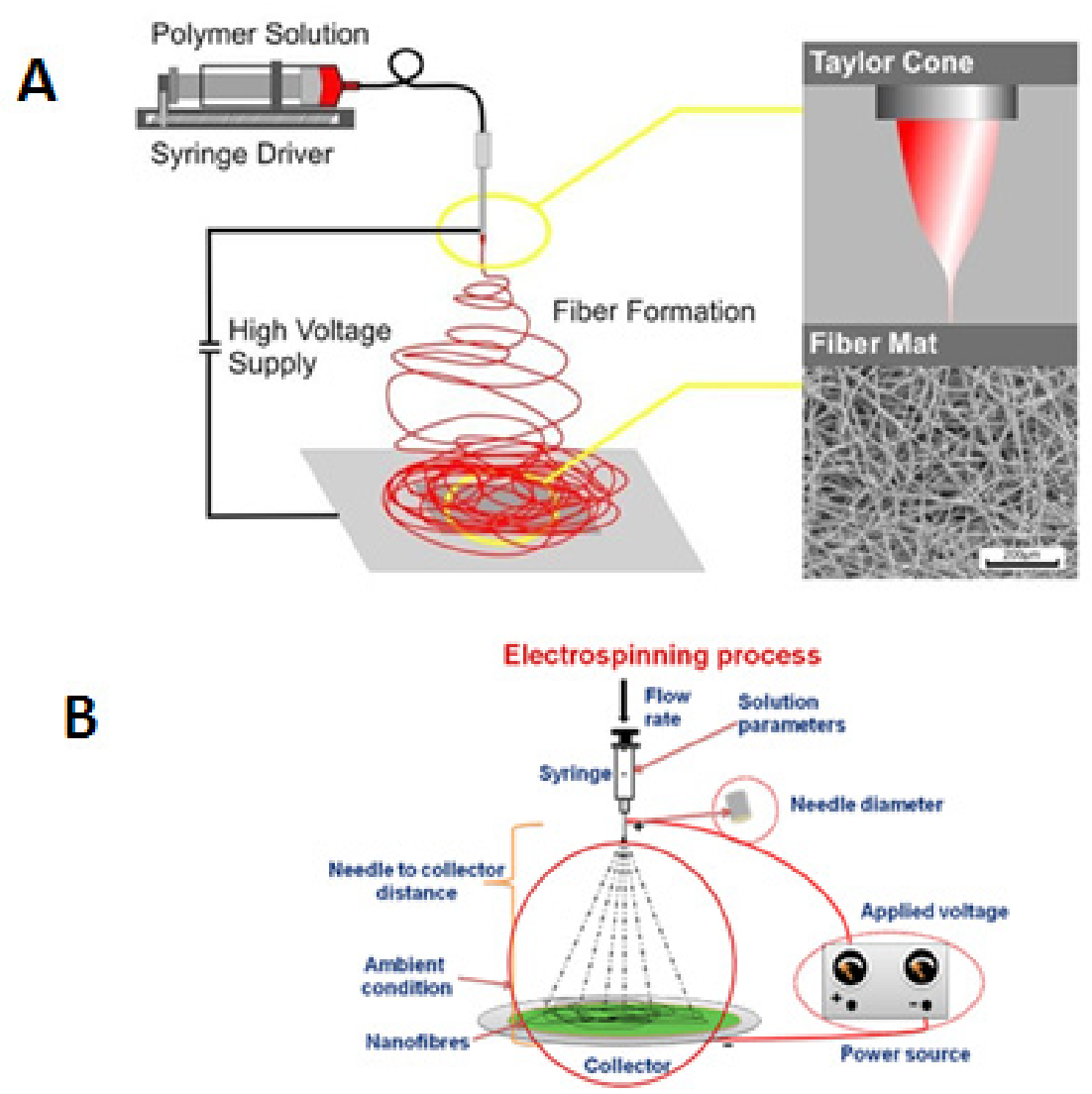

Fig.1. Schematic representation of the electrospinning system (A) and the factors affect electrospun fibers (B).

biocompatibility and low toxicity [5].

\section{Materials and Methods}

\section{Materials}

Poly $\varepsilon$-caprolactone (PCL) with average molecular weight $80,000 \mathrm{~g} / \mathrm{mol}$ and polyethylene oxide (PEO) with molecular weight 900,000 $\mathrm{g} / \mathrm{mol}$.), were purchased from Sigma Aldrich. Methanol was obtained from El-Nasr Company and chloroform was purchased from Fisher Scientific UK.

\section{Methods}

For investigation the change effect of parameters on the fiber morphology; different concentrations of PCL 8, 10 and $12 \%$ are used. The $10 \%$ PCL is treated for further investigation. PEO too with different concentrations 3, 6 and 9\% relative to weight of PCL is added to PCL solution for further work.

Then PCL 10\% and PEO 3\% are electrospun with different parameters: voltage 5, 10,15 and 20 $\mathrm{kV}$ in addition to use different distances between tip and collector; $6 \mathrm{~cm}, 8 \mathrm{~cm}, 12 \mathrm{~cm}$ and $14 \mathrm{~cm}$ and with different solvents (acetone, chloroform, methanol and specially for chloroform: methanol is used with different ratios; $3: 1,1: 3$, and 1:1 respectively. The viscosity and conductivity measured by Brookfield viscometer and using GMH 3430 conductivity meter of PCL are investigated with different concentrations, PCL / $\mathrm{PEO}$ ratio is also studied at different values of $\mathrm{PEO}$ to PCL ratio. Some of the electrospun fibers are investigated by field emission scanning electron microscope (FESEM). The average diameter of nanofiber and its normal distribution is obtained by at least 50 measurements on a typical FESEM image using Image J $1.40 \mathrm{G}$ software (NIH, USA).

Unless otherwise mentioned for the specific studied parameters: PCL with an optimized concentration $(10 \%)$ and PEO with an optimized concentration $3 \%$ relative to PCL are dissolved in a mixture of chloroform: methanol $(3: 1)$ for all samples. After dissolution of the polymer in the solvent the solution is introduced into $1 \mathrm{ml}$ syringe and injected through a stainless-steel blunt needle

Egypt. J. Biophys. Biomed. Engng. Vol. , (2018) 
$(0.90 \times 70 \mathrm{~mm} \mathrm{Bl} / \mathrm{Bl})$ for electrospinning. The Electrospinning process is performed with a feeding rate of $10 \mathrm{~mL} / \mathrm{h}$ using the syringe pump, an applied voltage of $20 \mathrm{kV}$, and a distance of 12 $\mathrm{cm}$ separates the tip of the needle and the collector.

\section{Results and Discussion}

\section{Polymer solution concentration}

Figure (2) illustrates the variation of morphology, formation of beads and distribution of the diameters for the obtained fibers with the change of PCL concentration of polymer solution. It is indicated from this figure that, at $8 \%$ concentration of PCL, there is a combination of beads and nanofibers while at $10 \%$ and $12 \%$ show beadless fibers. Also the fiber diameter increases with the increment of PCL concentration. This may be due to the following: at low concentration of the polymeric PCL solution ( $8 \%$ ), there is dilute solution too in the absence of polymer chain entanglement that allows the applied electric field and surface tension to break it into fragments before reaching the collector [6-7]. These fragments cause the formation of beads or beaded nanofibers. When enhance concentration of the PCL solution 10 to $12 \%$, this leads to an increase in viscosity, which increases the chain entanglement among the polymer chains. These chains entanglement overcome the surface tension and ultimately result in uniform beadless electrospun nanofibers. These results are compatible with the results obtained by (Haider et al., 2017) [8] and (Pillay et al., 2013) [3]. Furthermore, increasing the concentration beyond a critical value (above 12\%) hampers the flow of the solution through the needle tip (the polymer solution dries at the tip of the metallic needle and blocks it), which ultimately results in defective or beaded nanofibers.

\section{Ratio of $P E O$ relative to $P C L$}

Figure.3. shows FESEM micrographs of PCL: PEO at different ratio of PEO $(3 \%, 6 \%, 9 \%$ respectively) relative to $\mathrm{PCL}$ and the distribution of the fibers diameter as a function of PEO ratio. As indicated in this Fig., 3\% PEO, produces straight fibers while $6 \%, 9 \%$ PEO produce wrapped fibers. At the same time of fibers collection as same diameter of the tip of the syringe, the collection of the fibers is better for $3 \%$. Also the mean diameters of the collected fibers are increased with the enhancement of PEO ratio. This may be referred to enlargement of viscosity for the polymer solution due to increase in the ratio of $\mathrm{PEO}$, as $\mathrm{PEO}$ has a molecular weight $(900,000 \mathrm{~g} / \mathrm{mol})$ higher than that of PCL $(80,000 \mathrm{~g} / \mathrm{mol})$. This increment of viscosity results in an increase in the polymer chains entanglement which led to the observed enhancement in the fiber diameter. These findings are agreed with the study done by Son et al., (2004) [9].
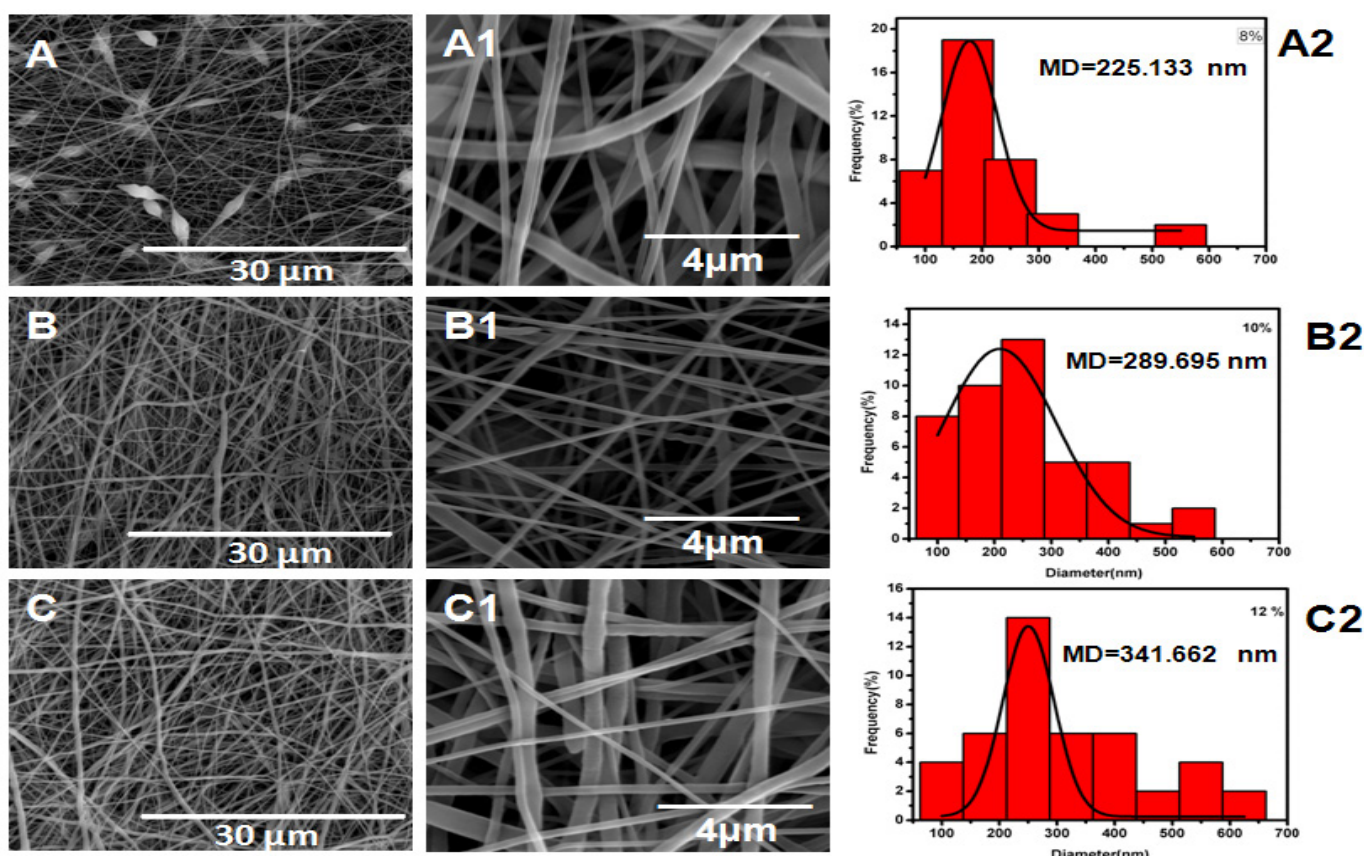

Fig.2. FESEM micrographs of electrospun PCL fibers with different concentrations. $(A, B, C)$ concentrations $(8$, $10 \& 12 \%)$ respectively at magnifications $4000 x$. (A1, B1\&C1) concentrations $(8,10 \& 12 \%)$ respectively at magnifications 30,000x. (A2, B2\&C2) distribution of fibers diameter.

Egypt. J. Biophys. Biomed. Engng. Vol., (2018) 

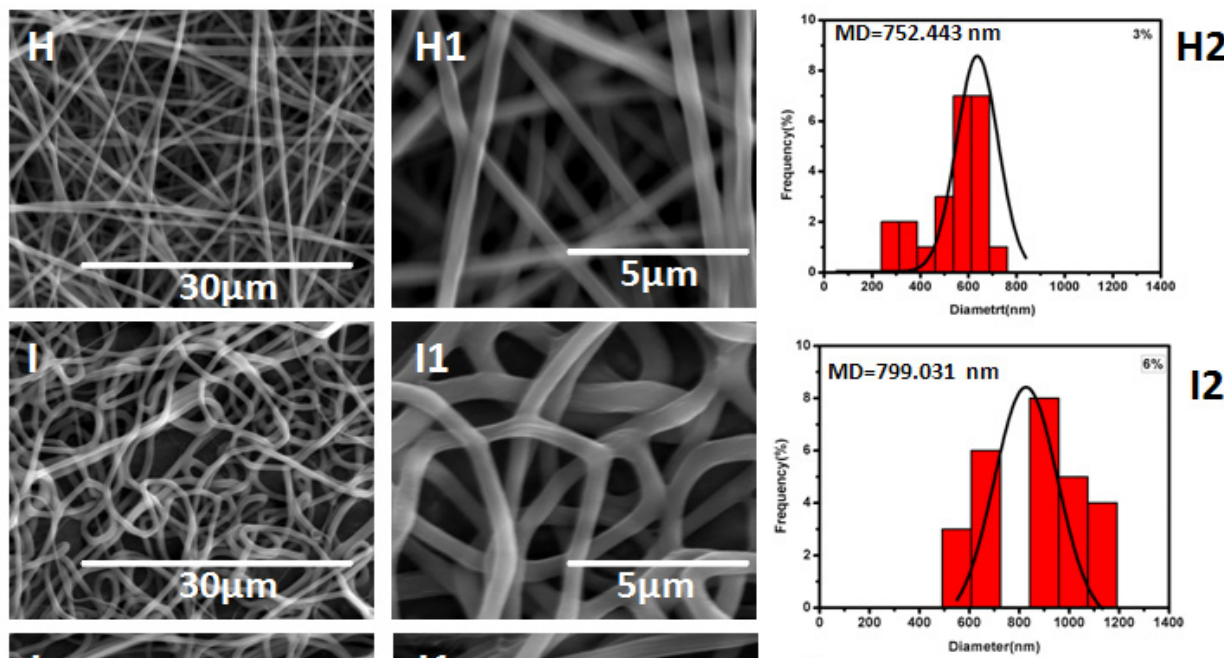

12
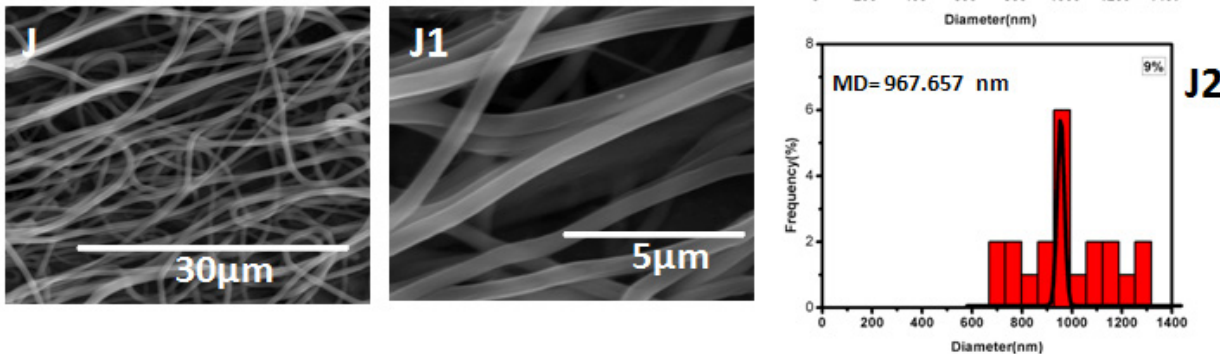

Fig .3. FESEM micrographs of co-polymer of PCL and PEO nanofibers with different ratios of PEO relative to PCL. (H, I, J) FESEM micrographs of $(3 \%, 6 \%, 9 \%)$ PEO respectively at magnification 4000x and (H1, I1, J1) at 15,000x. (H2, I2, J2) fibers diameter distribution at 3\%, 6\%, $9 \%$ of PEO respectively.

Viscosity and conductivity of polymer solution

Viscosity, polymer concentration, and polymeric molecular weight are related to each other. [1-10]. Table (1) illustrates viscosity of different solutions. As shown in this table; Viscosity of PCL solution is directly increased with the enhancement of polymer concentration due to great number of particles dissolves in the solvent. At a constant concentration of PCL $(10 \% \mathrm{wt} / \mathrm{v})$, the addition of PEO to PCL solution increases its viscosity. This may be due to the great value of molecular weight for PEO $(900,000 \mathrm{~g} / \mathrm{ml})$ when compares to PCL molecular weight $(80,000 \mathrm{~g} / \mathrm{ml})$. There is monotonous enlargement on the viscosity of $\mathrm{PCL} / \mathrm{PEO}$ polymer solution with the growth of PEO value .

Conductivity of the solution contains both PCL and PEO is greater than that for pure PCL which pointed to the following: addition of $\mathrm{PEO}$ to the PCL solution increases its conductivity. There is also monotonous increment in conductivity of solution with the PEO quantity. This may be refer to, the presence of more ion charges in the structure of PEO.
TABLE 1. Viscosity and conductivity for different solutions.

\begin{tabular}{|c|c|c|}
\hline 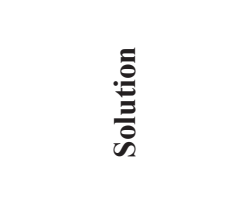 & 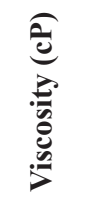 & 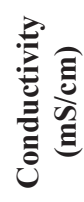 \\
\hline \multicolumn{3}{|c|}{ Base PCL solution } \\
\hline $8(\% \mathrm{w} / \mathrm{v})$ of $\mathrm{PCL}$ & 126 & 0.1 \\
\hline $10(\% \mathrm{w} / \mathrm{v})$ of $\mathrm{PCL}$ & 253 & 1.30 \\
\hline $12(\% \mathrm{w} / \mathrm{v})$ of PCL & 1100 & 1.25 \\
\hline \multicolumn{3}{|c|}{ PCL and PEO solution } \\
\hline $\begin{array}{c}\text { Ratio of PCL:PEO } \\
97: 3\end{array}$ & 768 & 0.75 \\
\hline $\begin{array}{c}\text { Ratio of PCL:PEO } \\
94: 6\end{array}$ & 1400 & 2.20 \\
\hline $\begin{array}{c}\text { Ratio of PCL:PEO } \\
91: 9\end{array}$ & 7370 & 3.06 \\
\hline
\end{tabular}




\section{The influence of different solvents}

The choice of solvent has a critical effect on the morphology of fibers (Fig.4). This fig. shows that, the output fibers of PCL-PEO polymer solution dissolves in acetone has morphology which differs than that dissolves in chloroform. For those dissolves in acetone, their fibers have random ribbon like shape which may be due to, the boiling point of acetone which not allows its complete dehydration prior to reaching the collector, thereby resulting in ribbon like flat nanofiber morphologies. The mean fiber diameter is increased for chloroform solvent than acetone. Also the simultaneous collection of the fibers on the collector is very weak. Dissolution of fibers in chloroform produces more improved nanofibers which appears homogenous in morphology. The copolymers of PCL-PEO not dissolve in methanol.

To achieve the desired porosity and nanofiber topographies a blend of two solvents (co-solvents) with different boiling points can be used. The combination of chloroform: methanol with different ratios: 1:1, 3:1, 1:3 respectively affects the properties of the formed fibers.

The copolymers not dissolve when the ratio of chloroform: methanol is 1:3. Fibers produce from PCL-PEO co- polymer dissolved in a mixture of chloroform: methanol (1:1) have randomly oriented fibers, with no homogeneity in their shapes showing smooth surface on some of them. Some others have rough surface in addition to another's have ribbon like shape. There is a wide distribution too for the fibers diameter. On the other hand, dissolution of the PCL-PEO copolymers in a mixture of chloroform: methanol with ratio (3:1) results in the formation of more aligned fibers with more homogeneity in their morphology and diameter distribution during electrospun. Distribution of the fibers dissolved in chloroform: methanol (1:1) is larger than those dissolved in chloroform: methanol $(3: 1)$.

All these changes may be as results of the different boiling points and volatility of the two solvents through which chloroform has a boiling point of about $61.2^{\circ} \mathrm{C}$ and has high intrinsic viscosity, while methanol has a boiling point of about $64.7^{\circ} \mathrm{C}$ and high dielectric constant. Therefore chloroform is more volatile than methanol. When the two solvents are mixed together with the ratio $1: 1$, the presence of methanol which has a high boiling point with high ratio which not allows its complete dehydration before reaching the collector. This results on the observed coagulation of the prepared fibers. On the other hand, increasing the ratio of chloroform to methanol is $(3: 1)$. This ratio results in appropriate value of viscosity which facilitates nanofiber solidification with the formation of more homogenous nanofibers. This conclusion is consistent with that obtained by Fong et al., (1999) [11] and Ki et al., (2005) [12].

\section{Influence of change the applied voltage}

Figure (5). Shows FESEM micrographs of the electrospun nanofibers for PCL-PEO polymer solution at two different magnifications and the distribution of their fibers diameter at different applied voltages $(5,10,15$ and $20 \mathrm{kV})$. As shown in this Fig, there is no big variation on the morphology such as homogeneity, alignment of the electrospun nanofibers under the influence of different voltages.

There is only a slight change on the diameter of the nanofibers with the variation of the applied voltage. Mean fiber diameter is increased from 514.434 at $10 \mathrm{kV}$ to 741.456 at $15 \mathrm{kV}$ then decreases to 586.668 at $20 \mathrm{kV}$ at constant values of other factors.

The first increase on the fiber diameter may refer to; increment of the applied voltage causes an increase in the applied electric field strength which led to an enlargement of the electric force which draws more polymer solution out of the spinneret this in turn causes larger fibers diameter. [13] The diminish in the diameter of the nanofibers with the enhancement of the applied voltage from $15 \mathrm{kV}$ to $20 \mathrm{kV}$ may be refer to the stretching of the chains polymer in correlation with the charge repulsion within the polymer jet at the same tip diameter of syringe. However at $5 \mathrm{kV}$, the applied voltage is small that cannot manage to deform all the spherical droplets into fibers. The combination of droplets and fibers are formed at this low voltage. This study of effect for different voltages on formed nanofibers is aligned with that mentioned by Bazbouz et al., (2008) [2]. 

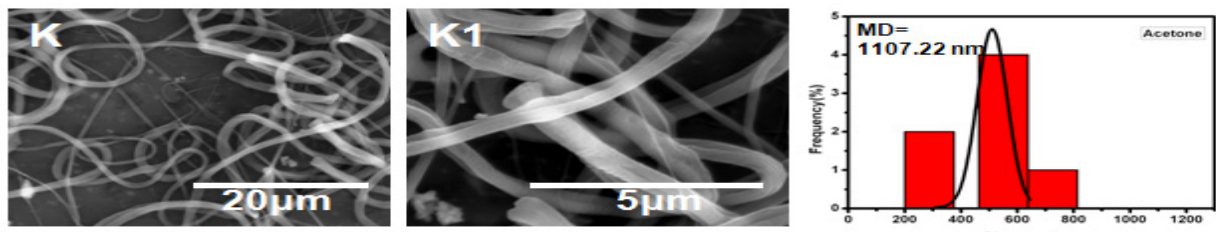

K2
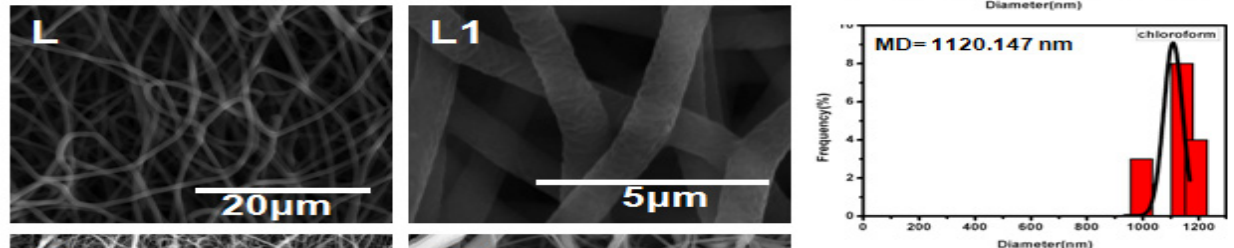

L2
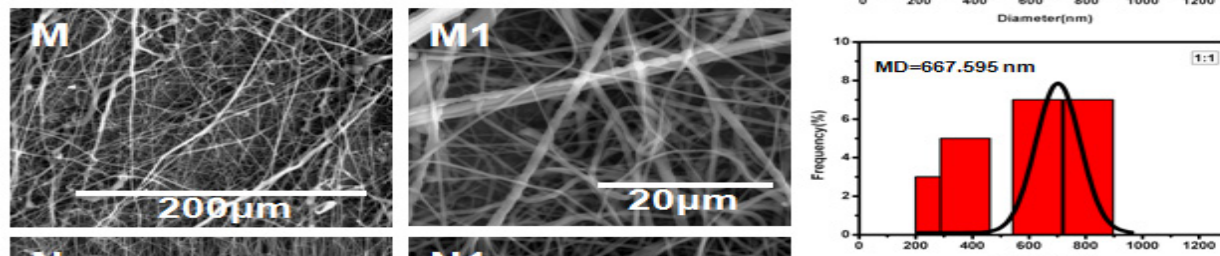

M2
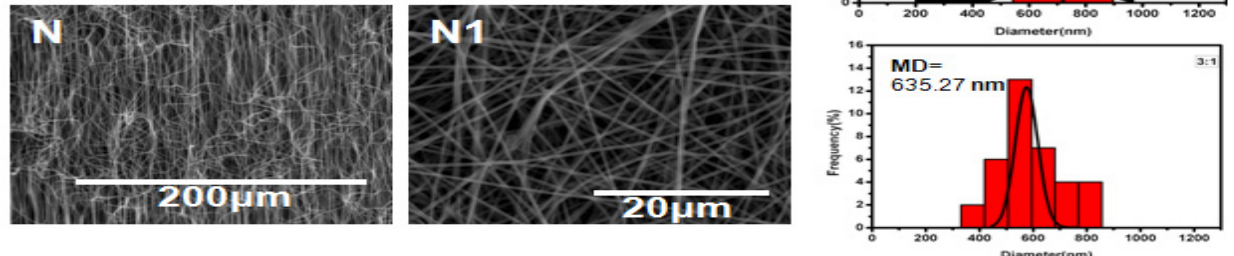

N2

Fig.4. FESEM micrographs of PCL-PEO nanofibers dissolve in various solvents at different values of magnification and distribution of diameters. (K, K1\& K2) for fibers dissolve in acetone, $(L, L 1, \& L 2)$ for fibers dissolve in chloroform.(M, M1\& M2) for fibers dissolve in chloroform :methanol 1:1 and (N, N1 \& N2) for the ratio 3:1.
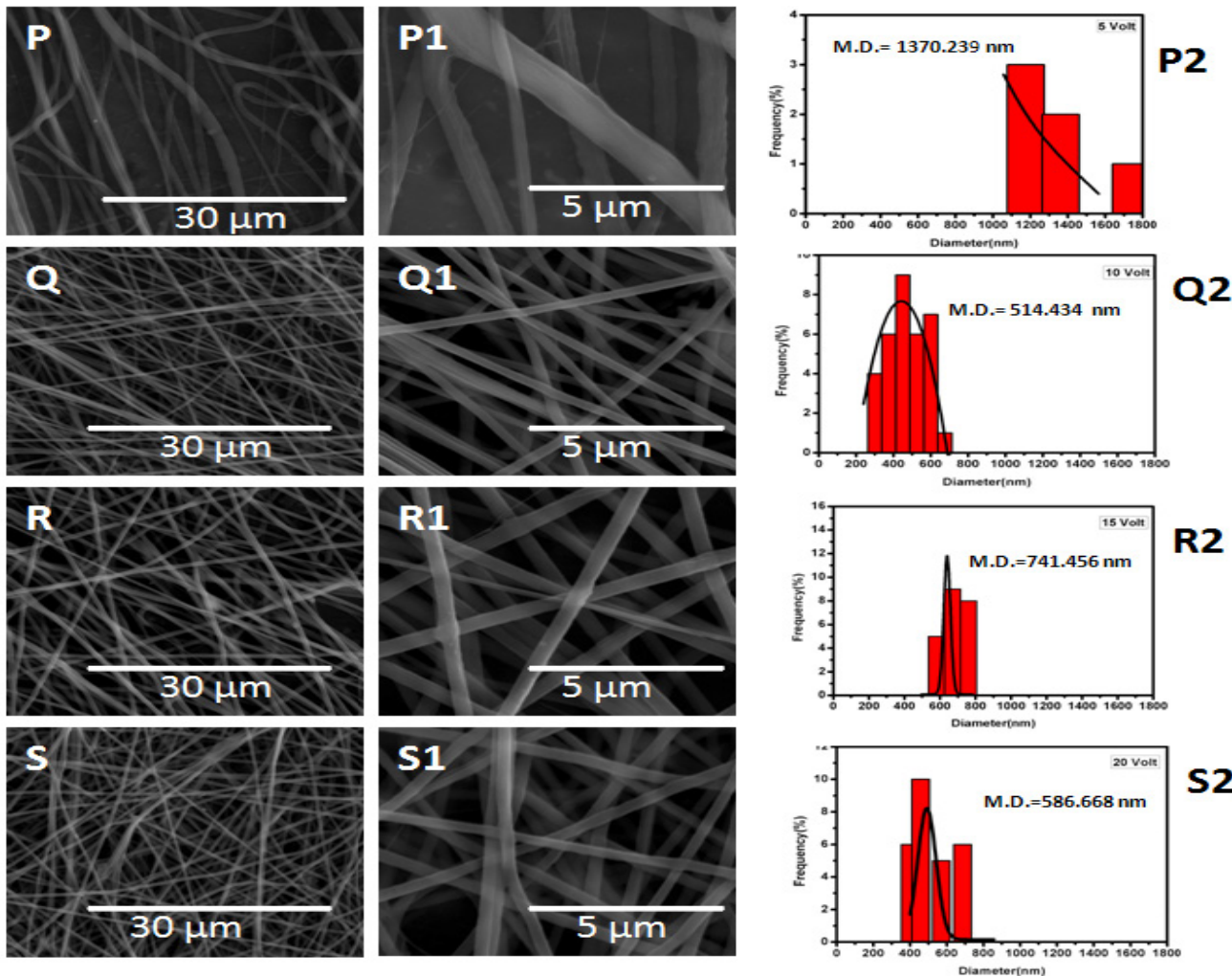

Fig. 5. FESEM micrographs of electrospun PCL/PEO with variation on the applied voltage and their fiber distribution at different magnifications. (P, P1\&P2) at $5 \mathrm{kV},(\mathrm{Q}, \mathrm{Q} 1 \& \mathrm{Q} 2)$ at $10 \mathrm{kV},(\mathrm{R}, \mathrm{R} 1 \& \mathrm{R} 2)$ at $15 \mathrm{kV}$ and $(\mathrm{S}, \mathrm{S} 1 \& \mathrm{S2})$ at $20 \mathrm{kV}$. 
Distance between the collector and tip of the syringe

SEM micrographs of the (PCL-PEO) nanofiber mats at various magnifications at different distances $(6,8,10 \& 12 \mathrm{~cm})$ are shown in Fig. (6). No beads are observed at distance investigation and this indicates that; the treatment at these distances has sufficient time to dry the fibers before reaching the collector. However, the increment of distance between the metallic needle tip and collector has an effect on the morphology and diameter of the electrospun nanofiber. This can be discussed as follow:
With an increase in the distance of the fibers movement towards the collector, the electric field strength has the opportunity to more stretch of the fiber and thus produces thinner fibers. In addition, with an increase in the distance, the time of the solvent evaporation will be extended which results in better drying, depositing and orienting of the fibers. On the other side, in case of a short electrospinning distance, the drying time is not big enough to fully evaporate the solvent before depositing the nanofibers on collectors. This conclusion in agreement with the study performed by Reneker and Chun, (1996) [14].
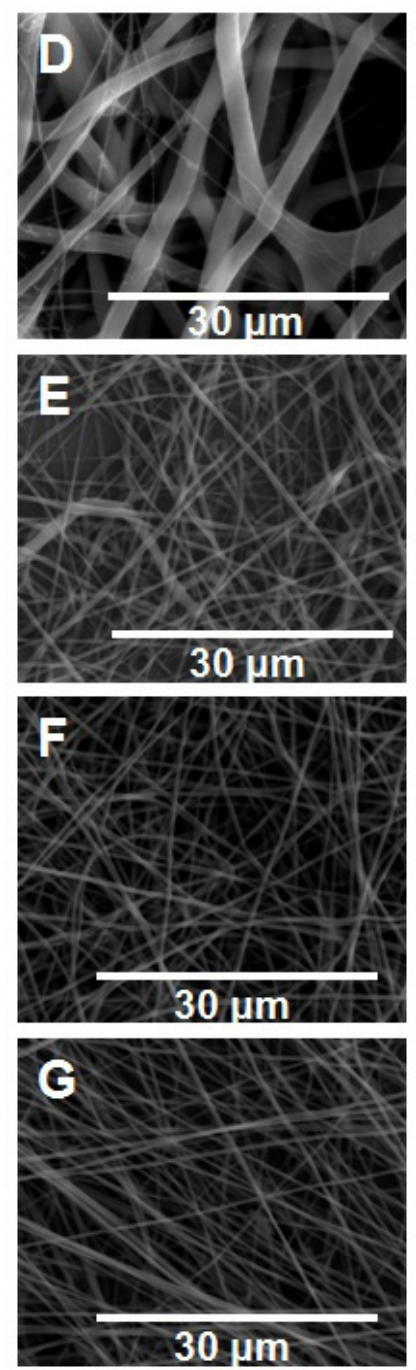
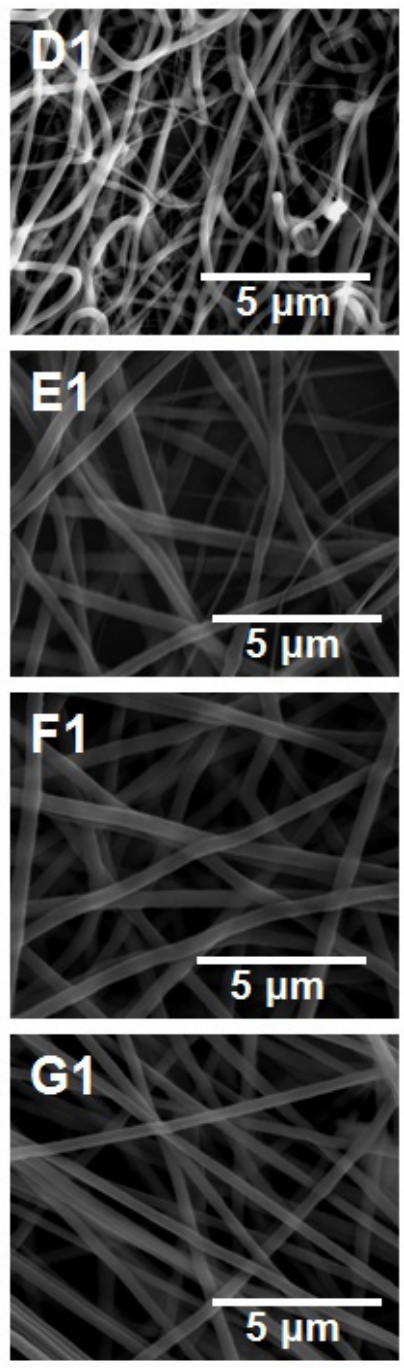
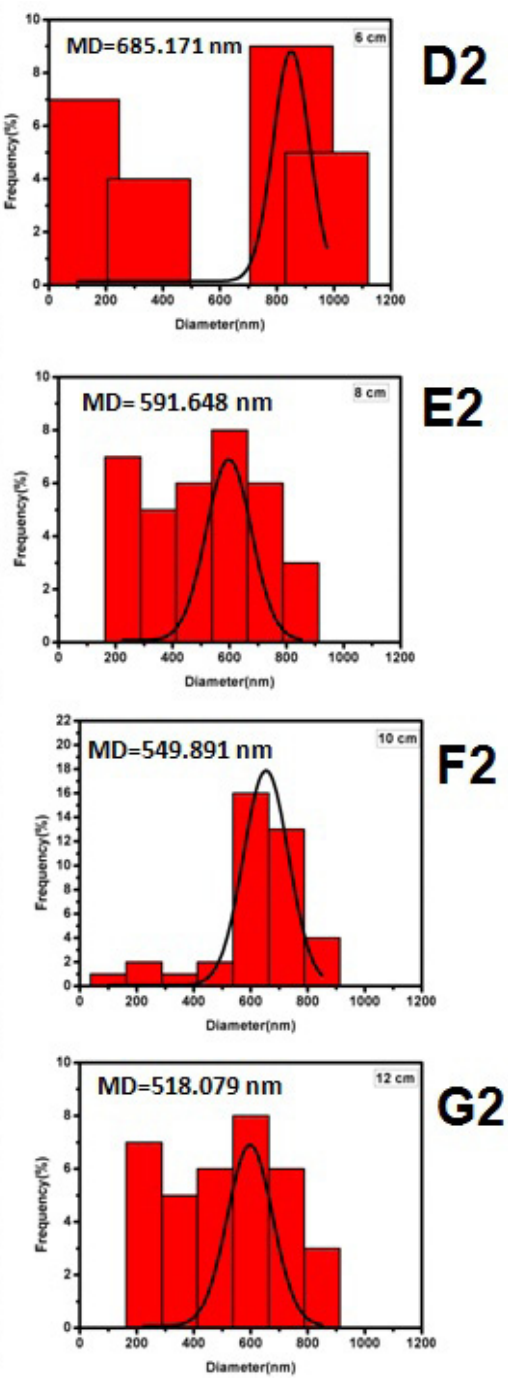

Fig. 6. FESEM micrographs of electrospun PCL/PEO with variation of the measured distance and their fiber distribution at different magnifications.(D,D1\& D2) at $6 \mathrm{~cm},(\mathrm{D}, \mathrm{D} 1 \& \mathrm{D} 2)$ at $8 \mathrm{~cm},(\mathrm{~F}, \mathrm{~F} 1 \& \mathrm{~F} 2)$ at $10 \mathrm{~cm}$ and $(\mathrm{G}, \mathrm{G} 1 \& \mathrm{G} 2)$ at12 $\mathrm{cm}$. 


\section{Conclusion}

Electrospinning is a versatile and low cost method for the production of micro and nanofibers. The characteristics of the obtained fibers such as, morphology, porosity, orientation and diameter can be controlled. This change enables to apply electrospun fibers for different applications. The present study investigates the effect of different parameters as follow; PCL concentrations, PEO to PCL ratio, viscosity, conductivity, applied voltage, different solvents and tip to collector distance on the production of electrospun fibers. The best optimum parameters obtained in this manuscript are as follow: PCL 10\%, PCL/PEO 97/3, $20 \mathrm{kV}$, $12 \mathrm{~cm}$ distance and chloroform: methanol 3:1 as solvent which used for further application in drug delivery.

\section{Refrences}

1. Botao S., Chengtie W., Jiang C., Dual drug release from electrospun poly(lactic-co-glycolic acid)/ mesoporous silica nanoparticles composite mats with distinct release profiles, Acta Biomaterialia, 8, 1901-1907, (2012).

2. Bazbouz M., Stylios G., Alignment and optimization of nylon 6 nanofibres by electrospinning, Journal of Applied Polymer Science, 107, 3023-3032, (2008).

3. Pillay V., Dott, C., Choonara, Y.E., Tyagi, C., Tomar, L., Kumar, P., du Toit, L.C., Ndesendo, V.M.K., A review of the effect of processing variables on the fabrication of electrospun nanofibers for drug delivery applications. $J$. Nanomate.,1, 22, (2013).

4. Repanas, Wolkers, Gryshkov, Müller Glasmacher , Pcl/Peg Electrospun Fibers as Drug Carriers for the Controlled Delivery of Dipyridamole, in silico and invitro pharmacology, 1(1:2),(2015).

5. Aluigi A., Varesano A., Montarsolo A., Vineis C., Ferrero F., Mazzuchetti G., Tonin C., Electrospinning of Keratin/Poly(ethylene oxide) Blend Nanofibers, Applied Polymer Science, 104,
863-870, (2007)

6. Athira K. ,Pallab S., Kaushik C., Fabrication of Poly(Caprolactone) Nanofibers by Electrospinning, Polymer and Biopolymer Physics Chemistry, 2( 4), 62-66,(2014).

7. Cipitria A., Skelton A., Dargaville R., Daltonac D. and Hutmacher D. W., Design, fabrication and characterization of PCL electrospun scaffolds-a review, Mater. Chem., 21, 9419, (2011).

8. Haider, S., Al-Zeghayer, Y., Ahmed Ali, F., Haider, A., Mahmood, A., Al-Masry, W., Imran, M., Aijaz, M., Highly aligned narrow diameter chitosan electrospun nanofibers, J. Polym. Res. 20(4), 1-11,(2013).

9. Son W., Youk J., Lee T., Park W., The effects of solution properties and polyelectrolyte on electrospinning of ultrafine poly(ethylene oxide) fibres, Polymer, 45, 2959-2966, (2004).

10. Sukigara S., Gandhi M., Ayutsede J., Micklus M., Ko F., Regeneration of Bombyx mori silk by electrospinning - part 1: Processing parameters and geometric properties, Polymer, 44(19), 57215727, (2003).

11. Fong H., Chun I., and Reneker D., Beaded nanofibers formed during electrospinning, Polymer, 40(16), 4585-4592, (1999).

12. Ki C., Baek D., Gang K., Lee K., Um I., Park Y., Characterization of gelatin nanofiber prepared from gelatin-formic acid solution, Polymer 46(14), 094-5102,(2005).

13. Demir M., Yilgor I., Yilgor E., Erman B., Electrospinning of polyurethane fibers, Polymer, 43, 3303-3309, (2002).

14. Reneker D., Chun I., Nanometre diameter fibres of polymer, produced by electrospinning. Nanotechnology, 7(3),216-223, (1996).

(Received6/12/2017 ; accepted 24 /1 / 2018) 


\title{
التحكم فى خواص الالياف المحضرة بطريقة الغزل الكهربى
}

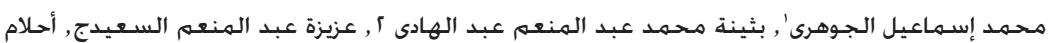

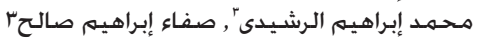

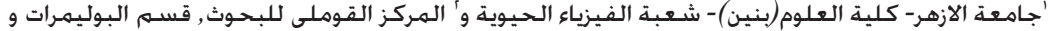

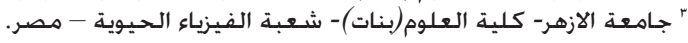

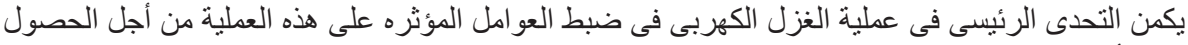

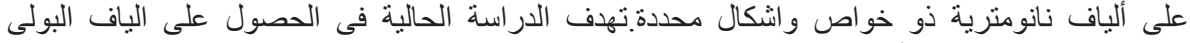

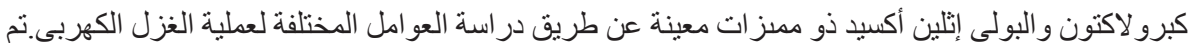

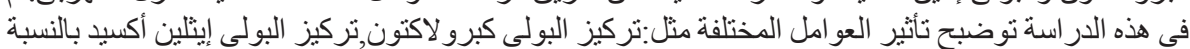

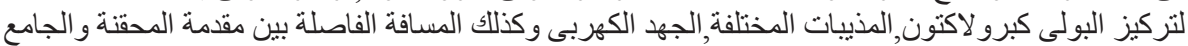

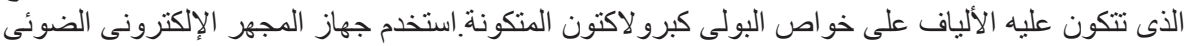

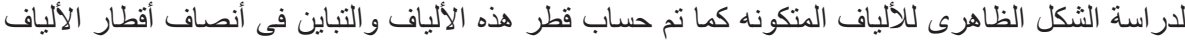

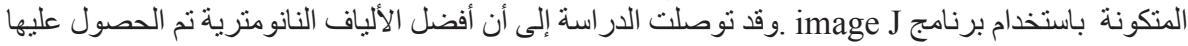

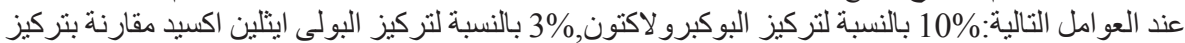

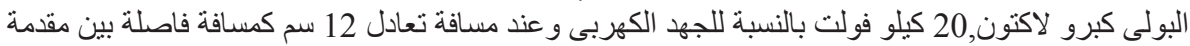

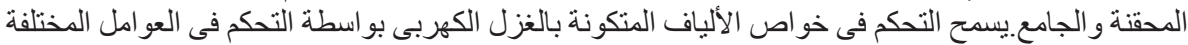
إلى إمكانية تطبيق هذه الألياف فى التطبيقات المختلفة.
\end{abstract}

